\title{
O DESGASTE FLUVIAL DA AMETISTA DE BREJAÚBA, MG: UM MÉTODO AUXILIAR DE PROSPECÇÃO
}

\author{
Pierre De Brot ${ }^{1}$, Joachim Karfunkel ${ }^{2}$, Augusto Fonseca Fernandes ${ }^{1}$ \\ 1 - Programa de Pós-Graduação em Geologia, Universidade Federal de Minas Gerais, Instituto de Geociências, Av. Antônio Carlos, 6.627 \\ Pampulha, CEP: 31270-902, Belo Horizonte, MG. andredebrot@yahoo.com.br; augffs@gmail.com \\ 2 - Instituto de Geociências-IGC/UFMG, Avenida Antônio Carlos, 6627 - Campus Pampulha, 311270-901 - Belo Horizonte, MG. \\ jkarfunkel@yahoo.com
}

Recebido em 20 de novembro de 2012; aceito em 6 de setembro de 2013

\begin{abstract}
RESUMO: A pesquisa aqui apresentada desenvolve um método para estimar a distância que a ametista percorreu no Ribeirão Brejaúba de sua rocha fonte para o seu local de recuperação no sistema fluvial a partir da análise do desgaste. Utilizando amostras que foram coletadas na sua própria origem, em laboratório, com os sedimentos do sistema fluvial simulou-se o desgaste de transporte semelhante ao do sistema fluvial com a utilização do de um tambor rotatório (tumbler). O desgaste foi determinado por uma lupa de mão de 10x e lupa binocular. As curvas de desgaste foram então desenvolvidas em tempo de rotação em relação à perda de peso. Ao comparar o desgaste das amostras a partir do sistema fluvial com as do tumbler, chegou-se à razão de 1 x 10 (distância percorrida no sistema fluvial versus a distância percorrida pela gema no tumbler), respectivamente. Para futura prospecção de ametista em sistemas fluviais com características similares ao da Brejaúba, este método permite a eliminação de muitas estações de amostragem, pois a distância até a fonte pode ser melhor estimada. Representa um método auxiliar de prospeç̧ão aluvionar, maximizando o custo/ benefício em relação ao método convencional. Esse método pode ser usado em outros minerais gemológicos como foi realizado para a brasilianita da área de Mendes Pimentel, em Minas Gerais.
\end{abstract}

Palavras Chaves: desgaste fluvial, ametista, prospecção

ABSTRACT: FLUVIAL WEAR OF THE AMETHYST FROM BREJAÚBA, MG: AN AUXILIARY METHOD FOR ALLUVIAL PROSPECTING. . The researCh presented here develops a method for estimating the distance that alluvial amethyst has traveled from its source rock to its recovery site in the fluvial system of the Ribeirão Brejaúba from analysis of the fluvial wear shown on experimental samples. Using samples collected from the source region, they were tumbled in the laboratory with sediments from the fluvial system so as to simulate the wear from transport in that fluvial system. The wear was determined by a hand loupe and 10x binocular loupe. Graphs were then developed showing the time of rotation versus the weight loss. By comparing the wear of samples from the fluvial system to that in the tumbler a ratio of 1 to 10 , respectively, was found. For future prospecting for amethyst in fluvial systems similar to that of Brejaúba, this method permits elimination of many sampling positions because the distance to the source may be better estimated. This gives an auxiliary method to traditional follow-up methods of prospecting maximizing cost/benefits of exploration. This method may be used on other gemstones as has been demonstrated for brazilianite from the Mendes Pimentel area in Minas Gerais.

Keywords: fluvial wear, amethyst, prospecting

\section{INTRODUÇÃO}

Cada mineral, em função de suas propriedades físicas, químicas e cristalográficas, possui uma taxa de dispersão específica. Portanto, um dos métodos para a localização de jazidas primárias passa pelo conhecimento das ocorrências secundárias em sistemas fluviais. 0 desenvolvimento desta metodologia permite definir critérios para a pesquisa aluvionar (Chaves et al. 2002).

Os estudos sobre a simulação do desgaste de rochas em laboratório se iniciaram há pouco mais de 130 anos, com Daubrée 1879 (in Kuenen 1956). Entretanto, verifica-se uma notável escassez de pesquisas sobre desgaste de pedras coradas ao longo do sistema fluvial a partir da área fonte. A metodologia consiste em (i) levantamentos no campo, com a coleta de amostras na área fonte e ao longo do sistema fluvial, (ii) simulação no tumbler (tambor rotatório) do desgaste "artificial" das amostras coletadas na área fonte em laboratório, e (iii) comparação do desgaste das gemas em sistema fluvial (natural) e no tumbler (artificial) (Debrot 2008, 2013).

O objetivo precípuo da pesquisa é a criação de padrões que determinem o desgaste da ametista de Brejaúba, com base nos estudos desenvolvidos durante o mestrado (Debrot 2008) e doutorado (Debrot 2013) em função da distância percorrida no sistema fluvial, para que em casos futuros de fonte(s) desconhecida(s), possam ser localizada(s) a(s) área(s) fonte(s) da gema, (Debrot et al. 2013). Desta forma o método representa uma ferramenta auxiliar na prospecção aluvionar.

\section{LOCALIZAÇÃO}

O distrito de Brejaúba localiza-se na porção sudeste do Estado de Minas Gerais e pertence ao Município de Conceição do Mato Dentro, (Fig. 1).

A região de Brejaúba apresenta topograficamente configuração bastante irregular, com relevo extremamente dissecado, com vales encaixados e enconstas muito íngremes. $\mathrm{Na}$ área em estudo destaca-se o Rio do Peixe, o Ribeirão Brejaúba e os Córregos das Posses e do Caracol (Fig. 2).

O clima da região apresenta temperaturas em média de $20,1^{\circ} \mathrm{C}$, sendo julho o mês mais frio com médias de $18,0^{\circ} \mathrm{C}$ e o período mais quente se estendendo de outubro a março com média de 
23, $2^{\circ} \mathrm{C}$ (INMET). $\mathrm{O}$ índice pluviométrico anual é de $1521 \mathrm{~mm}$. A vegetação original encontra-se substituída por pastagens e lavoura de subsistência e em poucos locais podem ser visualizados nichos de Mata Atlântica.

A ocorrência de ametista está localizada a $1.500 \mathrm{~m}$ da confluência do Córrego das Posses com o Ribeirão Brejaúba e a $4.000 \mathrm{~m}$ antes da confluência do Ribeirão Brejaúba com o Rio do Peixe (Fig. 2).

\section{GEOLOGIA}

A região de Brejaúba encontra-se incluída na unidade Geotectônica denominada Província Mantiqueira (Almeida \& Hasui 1984), sendo uma entidade geotectônica, instalada a leste do Cráton do São Francisco, ao final do Neoproterozóico e início do Paleozóico. No seu setor setentrional, compreendem basicamente rochas pré-cambrianas, em parte afetadas pelo Ciclo Brasiliano constituindo o cinturão chamado de Faixa de Dobramentos Araçuaí.

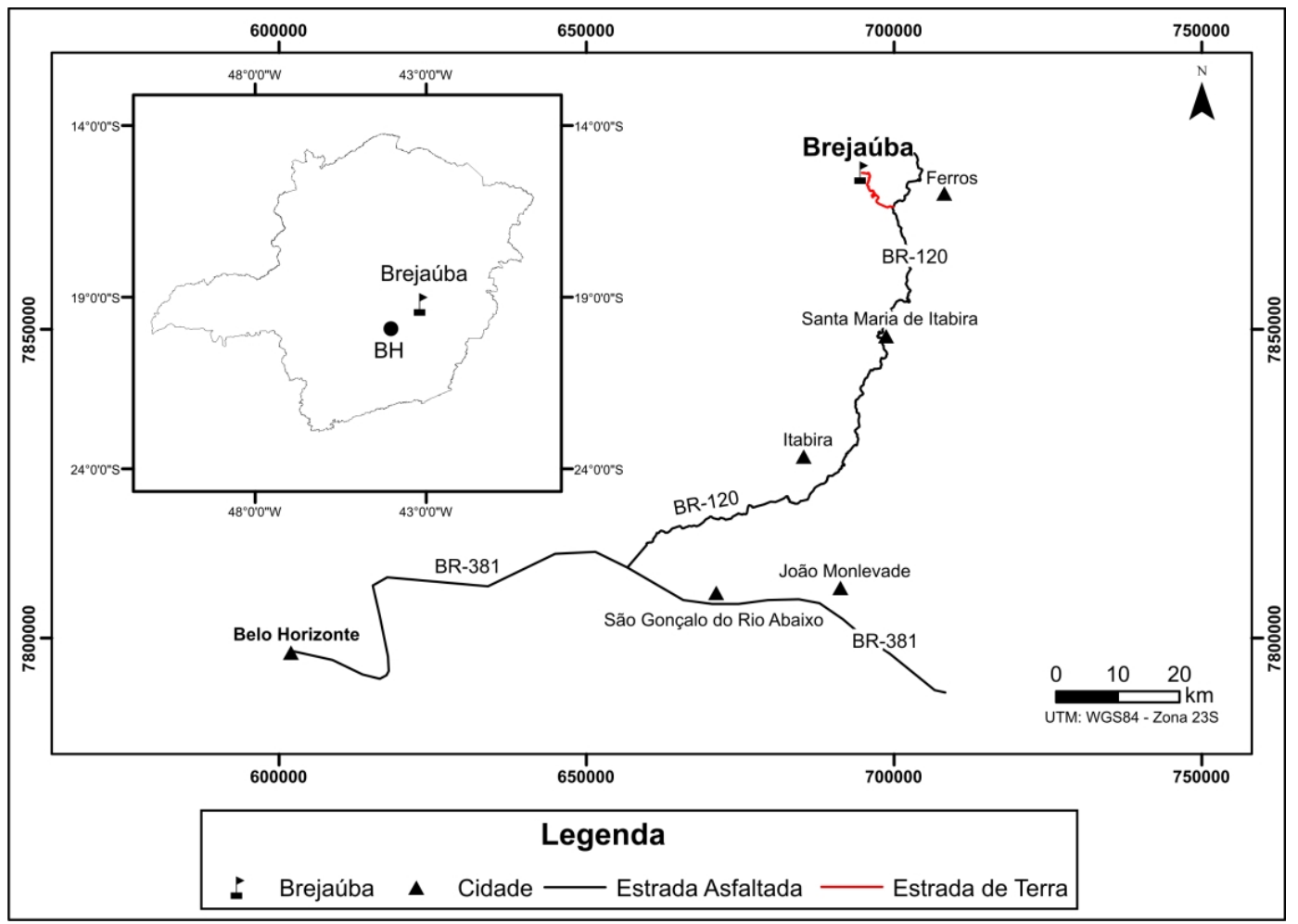

Figura 1 - Localização de Brejaúba (B), no Estado de Minas Gerais em relação à Belo Horizonte (A).

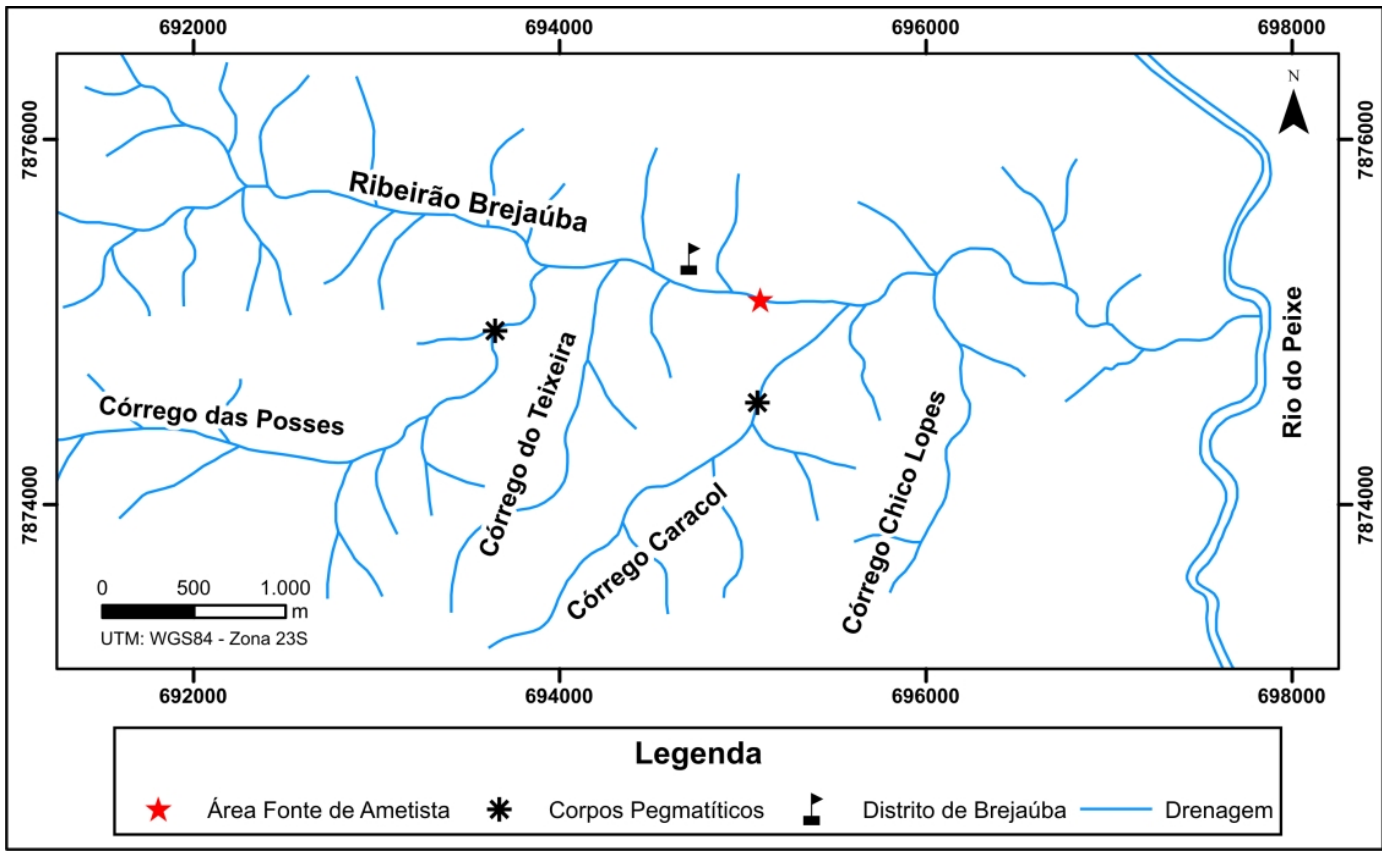

Figura 2 - Localização do Vilarejo de Brejaúba (1) e da ocorrência de ametista no Ribeirão Brajaúba (2). 
A geologia da área é caracterizada por uma sequência vulcano-sedimentar associada a um evento granítico pertencente à Suíte Borrachudos, (Netto et al.1998), de idade 1,7 Ba (Dossin et al. 1993). De acordo com Grossi-Sad et al. (1997), o Vilarejo de Brejaúba está incluída na ambiência geológica do Proterozóico Médio, Unidade Metaígnea Conceição do Mato Dentro.

Os principais tipos de associações de rochas intrusivas individualizadas na Folha de Conceição do Mato Dentro, na região estudada, são a Unidade Metaígnea Conceição do Mato Dentro, envolvendo principalmente termos ácidos subvulcânicos até vulcânicos e Suíte Borrachudos, com vários corpos de granitos e um quartzo monzonito. Ainda autores como Dussin (1994) definem áreas pertencentes à Suíte Borrachudos, Suíte Guanhães ou simplesmente gnaisses Arqueanos.

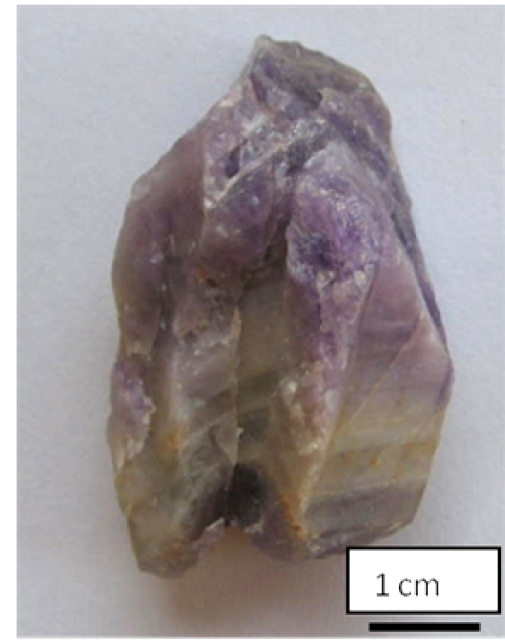

Figura 3 - Ametista coletada na área fonte do Ribeirão Brejaúba, MG.

No centro do Vilarejo Brejaúba encontrou-se uma ocorrência de veio de quartzo subvertical, parcialmente de cor violeta, o que justifica sua denominação de quartzo-ametista (Schumann 2007), com $1,7 \mathrm{~m}$ de espessura e mais de $10 \mathrm{~m}$ de extensão, encaixado em gnaisse, cortando a drenagem perpendicularmente. $O$ quartzo-ametista é de qualidade ornamental, esbranquiçado e leitoso, localmente violeta (Fig. 3), tendo sido extraído no final do século $X X$, entretanto, por apresentar qualidade inferior, não teve mercado de venda compensador e sua extração (realizada por cerca de 12 meses) foi paralisada.

\section{MATERIAIS E MÉTODOS}

O trabalho de campo foi desenvolvido com coleta de amostras ao longo do Ribeirão Brejaúba, a partir da área fonte da ametista, seguindo por $4 \mathrm{Km}$ até a sua confluência com o Rio do Peixe. No
Ribeirão Brejaúba a velocidade média (medido no mês de junho) de corrente no movimento laminar é de $0,37 \mathrm{~m} / \mathrm{s}$ e no turbulento de $0,42 \mathrm{~m} / \mathrm{s}$ e sua largura/profundidade em torno de $2,0 \mathrm{~m} / 30-50 \mathrm{~cm}$, respectivamente e sua vazão é de aproximadamente $1,135 \mathrm{~m}^{3} / \mathrm{s}$.

Ametistas obtidas na área fonte da região estudada foram selecionadas, e levadas ao tumbler, para simulação do desgaste em laboratório, com sedimentos do próprio local, após a sua análise granulométrica ( $28,6 \%$ de cascalho, $58,8 \%$ de areia e $12,6 \%$ de argila/silte), durante 40 horas. Em intervalos de 10 horas as amostras de ametista foram retiradas, pesadas e fotografadas. Sedimentos de composição diferente resultam em desgastes diferenciados (Debrot 2008, 2013).

O equipamento denominado tumbler (Fig. 4), de amplo uso em desgaste e polimento de pedras coradas, é um cilindro com eixo horizontal, utilizado na presente pesquisa para simular o desgaste no sistema fluvial. É acoplado a um motor que promove o movimento de rotação, fazendo com que o material existente dentro dele (ametista, sedimentos e água) tenha um movimento em regime de cascata.

Os desgastes superficiais das amostras do tumbler foram comparados, na lupa de mão de 10x, binocular e lupa binocular, com as coletadas no sistema fluvial. Os resultados obtidos indicaram a relação de 10:1 do tumbler para o sistema fluvial, (10 Km que a gema percorre no equipamento correspondem a $1 \mathrm{Km}$ de desgaste no sistema fluvial, Debrot 2008), dado este de extrema importância já que trabalhos anteriores (e.g. Kuenen 1956) relacionavam o desgaste superficial apenas em função do tempo percorrido no tumbler e não da distância.

\section{RESULTADOS}

Comparou-se os graus de desgaste das amostras submetidas ao processo de simulação no tumbler com aquelas coletadas no sistema fluvial. A razão 10:1 (distâncias percorridas no tumbler e no sistema fluvial, respectivamente) foi confirmada para todas as amostras. A Fig. 5 apresenta a imagem de uma das ametistas da área fonte, e ainda o grau de desgaste semelhante de uma amostra que percorreu uma distância de $4 \mathrm{Km}$ no sistema fluvial comparada com 40 horas de desgaste no tumbler (equivalente a $4 \mathrm{Km}$ ).Com os resultados obtidos em laboratório, elaborou-se a curva de desgaste da ametista de Brejaúba. No eixo " $y$ " foi plotada a porcentagem de perda de peso ocorrida no tumbler e no eixo " $x$ " à distância percorrida no sistema fluvial ao longo de 4 $\mathrm{Km}$ a partir da área fonte, (Fig. 6). 

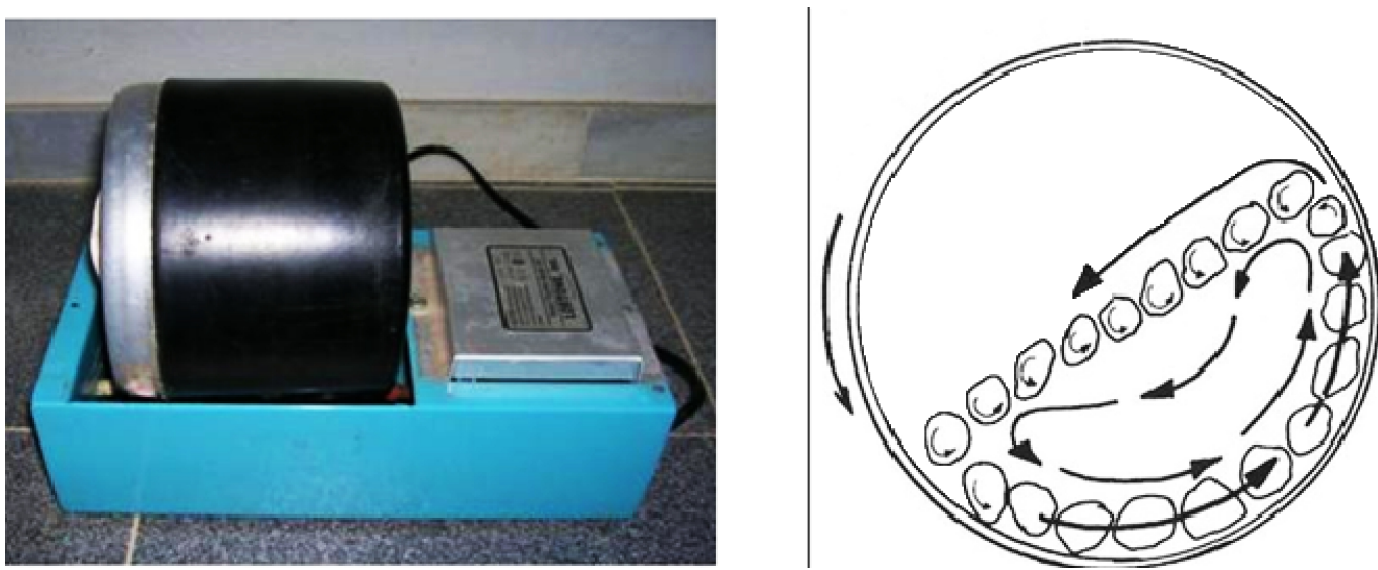

Figura 4 - Tumbler (à esquerda) usado para o desgaste da ametista em laboratório, e o interior do tumbler mostrando o regime de cascata (à direita, segundo Victor \& Victor 1959). (direction of barrel rotation = direção da rotação do tambor).

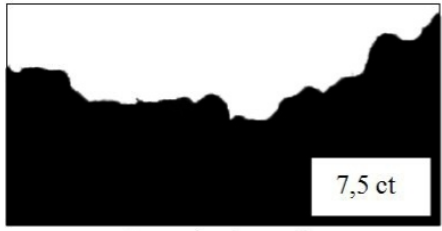

Ametista da área fonte.

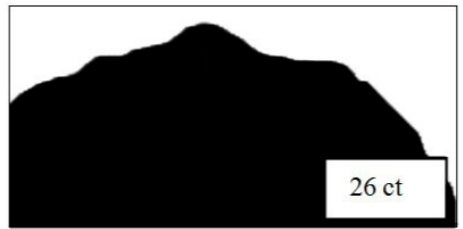

A $4 \mathrm{Km}$ coletada no sistema fluvial.

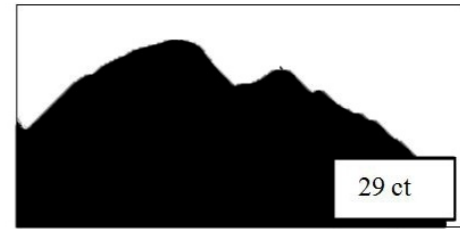

A $4 \mathrm{Km}$ de desgaste no tumbler.

Figura 5 - Amostra de ametista coletada na área fonte e a $4 \mathrm{Km}$ no sistema fluvial, comparadas com a amostra desgastada no tumbler após 40 horas de desgaste ( $4 \mathrm{Km}$, à direita), com aumento de $50 \mathrm{x}$.

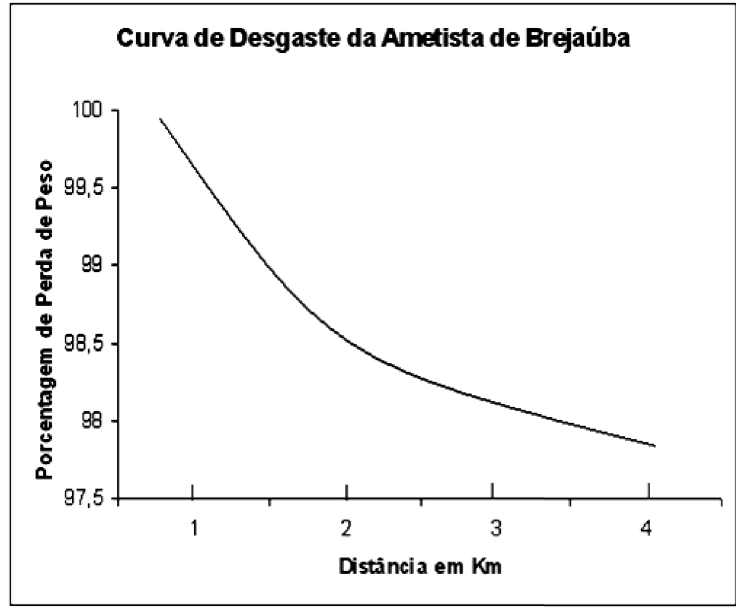

Figura 6 - Curva de desgaste da ametista de Brejaúba, MG.

\section{DISCUSSÃO E CONCLUSÕES}

A ametista de Brejaúba apresenta um desgaste maior nas primeiras centenas de metros e em seguida há uma tendência à sua estabilização. A cada $1.000 \mathrm{~m}$ que a amostra é desgastada no tumbler, existe uma correspondência de em torno de $10 \%$ no sistema fluvial do Ribeirão Brejaúba, o que permite expressar o desgaste em função da porcentagem de perda de peso versus distância percorrida, e não mais simplesmente em função do tempo de desgaste.
Se a fonte de uma gema é desconhecida, diversas estações de lavagem no método tradicional follow-up podem ser eliminadas pela estimativa da distância real até a fonte (desconhecida), baseandose no desgaste fluvial, um método auxiliar de prospecção aluvionar que maximiza o custo/benefício em relação ao método de prospecção convencional. O método pode ser utilizado para outras gemas, como já realizado para a localização da área fonte no caso da brasilianita do Córrego Indaiá, na região de Mendes Pimentel MG, (Debrot et. al. 2013).

Comparando o método follow-up convencional com o método sugerido, para uma distância de desgaste correspondente a $4 \mathrm{Km}$, percebe-se a razão custo benefício: no primeiro são 15 pontos de prospecção (Fig. 7), partindo-se do ponto onde a amostra foi encontrada (1) no sistema fluvial até a localização do ponto da área fonte (15). No método proposto são necessários apenas 4 pontos (Fig. 8): (1) onde a amostra foi prospectada até a descoberta do ponto da área fonte (4), com apenas dois pontos intermediários: (2), (que está a uma distância inferior a $4 \mathrm{Km}$ eliminando-se assim a necessidade de prospecção no ponto (2a) no respectivo subafluente) e (3), (a uma distância correspondente a 4 $\mathrm{Km}$ em relação à amostra 1 ). 


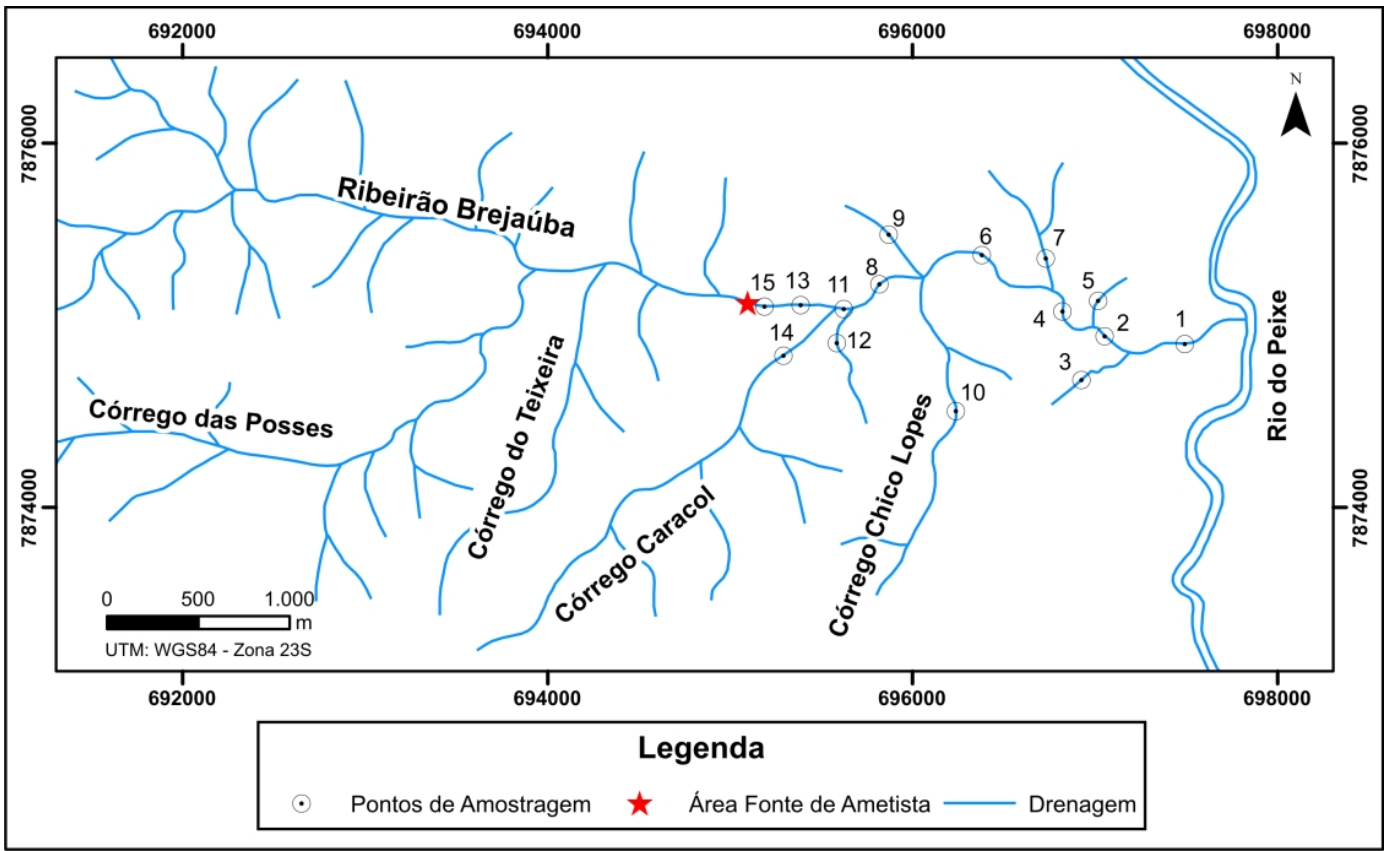

Figura 7 - Pontos prospectados pelo método convencional, na busca da área fonte (A.F.).

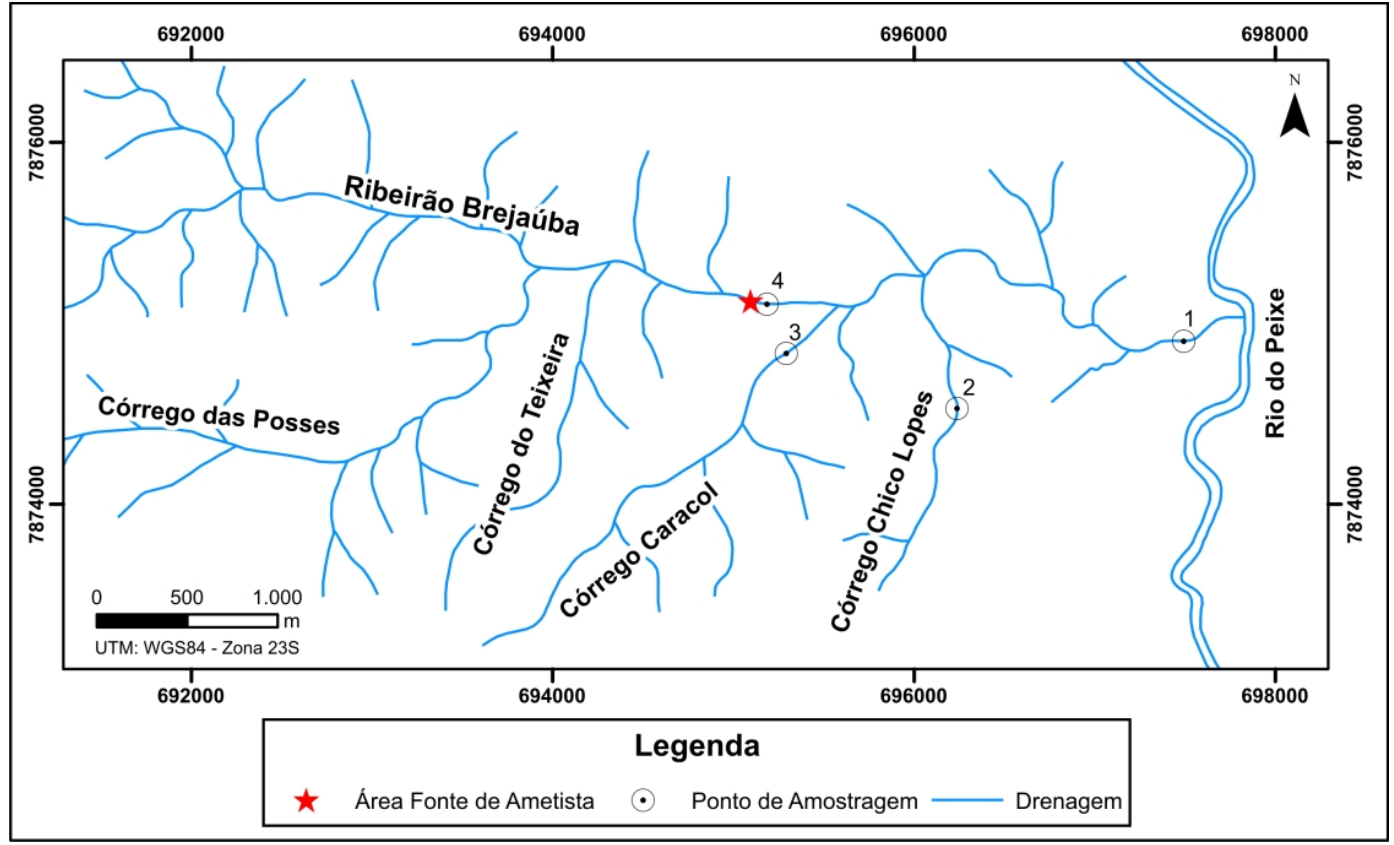

Figura 8 - Pontos prospectados pelo método proposto, na busca da área fonte (A.F.).

Esse procedimento representa um método auxiliar de prospecção, para amostras de ametista coletadas em sistemas fluviais, com características morfológicas, sedimentológicas e velocidades de corrente semelhantes ao do Ribeirão Brejaúba, em caso de fontes desconhecidas, propiciando a descoberta de áreas fontes.

Na região de Mendes Pimentel, MG, o método proposto possibilitou a descoberta da área fonte de brasilianita prospectada no Córrego Indaiá, (Debrot et. al. 2013) demonstrando a efetividade do processo em questão.

\section{AGRADECIMENTOS}

Os profissionais listados a seguir colaboraram nos trabalhos de campo, nas discussões críticas e com sugestões construtivas na elaboração na presente pesquisa: Prof. Dr. Herbert Pöllman (Inst. De Mineralogia, Univ. de Halle, Alemanha); Prof. Dr. Hans Joachim Kleebe (Inst. De Mineralogia, Univ. Darmstadt, Alemanha); Prof. Dr. Heinrich Karfunkel (Inst. De Química, Univ. de Tübingen, Alemanha, Aposentado); Dr. Donald Hoover (U.S.G.S Denver, CO, Estados Unidos, Aposentado); os autores ainda agradececem o apoio logístico do Dept. de Geologia 
do IGC, UFMG (curso de pós graduação) e do Centro Federal de Educação Tecnológica de Minas Gerais (Dept. de Química e Dept. de Engenharia de materiais).

\section{REFERÊNCIAS BIBLIOGRÁFICAS}

Almeida F.F.M. \& Hasui Y. (Eds.) 1984. O Pré-Cambriano do Brasil. Edgard Blücher, SP, 378 pp.

Chaves M.L.S.C., Karfunkel J., Medeiros A.B., Scholz R. 2002. Prospecção aluvionar aplicada a alguns minerais gemológicos de MG: diamante, crisoberilo e topázio. Ouro Preto, Ver. Esc. Minas, 55:1-13.

Debrot P.A.F. 2008. O Desgaste Fluvial de Minerais Gemológicos como Método para a Localização Aproximada da Área Fonte: Estudo de Casos. Dissertação de Mestrado, Instituto de Geociências, Universidade Federal de Minas Gerais. 80 p.Debrot P.A.F.. 2013. Determinação de áreas fontes de minerais gemológicos através da análise do desgaste fluvial. Tese de Doutorado, Instituto de Geociências, Universidade Federal de Minas Gerais. $189 \mathrm{p}$

Debrot P., Karfunkel J. \& Pöllmann H. 2013. Fluviatiler Abnutzunsgrad von Edelsteine als Mittel zur Bestimmung der Entfernung zur Quelle: Fallstudie von Brasilianit aus Mendes Pimentel, MG, Brasilien. Aufscchluss, 63(2): No prelo

Dossin I.A., Dossin T.M., Charvet J., Cocherie A. \& Rossi P., 1993. Single-zircon dating by step-wise Pb-evaporation of Middle
Proterozoic magmatism in the Espinhaço Range, southeastern São Francisco Craton (Minas Gerais, Brazil). In: SBG, Simp. Craton São Francisco, Salvador, Anais, 1:39-42

Dussin T.M. 1994. The Borrachudos Suíte, Mesoproterozoic Atype Granitic Magmatism in the Southeasterns São Francisco Cráton (SE Brazil). Tese de Doutorado, Université D' Órleans, $200 \mathrm{p}$.

Grossi-Sad J.H., Mourão M.A.A., Guimarães M.L.V., Knauer L.G. 1997. Geologia da Folha de Conceição do Mato Dentro. In: Grossi-Sad, J.H., Lobato, L.M., Pedrosa-Soares, A.C., SoaresFilho, B.S. (Eds). Projeto Espinhaço (textos, mapas e anexos). Belo Horizonte, COMIG, p. 25.

Google Maps. Disponível em: <http/www.googlemaps.com.br>. Acessado em 12 fev 2012.

INMET- INSTITUTO NACIONAL DE METROLOGIA. Disponível em: http//WWW.inmet.gov.br. Acessado em 12 fev 2012

Kuenen, P.H. 1956. Rolling by current, Pt 2 of experimental abrasion of pebbles. Rolling by current. Jour. Geol., 64:336368.

Netto C., Araújo C., Pinto C.P., Drumond J.B.V. 1998. Projeto Leste-Província Pegmatítica Oriental, Belo Horizonte, CMMG/CPRM, Relat. Final, 223 p.

Schumann W. (Ed.) 2007. Gemstones of the world. Sterling Publishing Co. Inc., New York, 280 pp.

Victor A.E. \& Victor L.M. (Eds.) 1959. Gem tumbling Ed. V.A. Shop, Washington, ( $9^{\text {th }}$ ed.), 54 pp. 